\title{
Crustacean aquaculture
}

\section{By A. Walker, RHM Research, Lord Rank Research Centre, Selby Road, Whitley Bridge, Goole, North Humberside}

The predictions made some time ago that the sea would yield a bountiful harvest for aquaculture ventures are proving to be untrue. The raising of animals in what is effectively an uncontrolled environment has given rise to problens in many aspects of the process.

The aquaculture system in its simplest form consists of a portion of beach cordoned off by a mesh fence. The principle behind the system is that tidal action brings about a change of water and provision of fresh food. It is essential that the area remains submerged during the ebb-tide. One of the major problems associated with a coastal aquaculture system is the provision of adequate rations for the animals, since there is little control of the quantity and type of food material. Such systems are generally extensive i.e. a low stocking density of animals is used. In addition to the nutritional aspects there are other problems relating to pollution, predation and poaching, all of which reduce the efficiency of this form of marine farming.

In view of this, the problem of improving husbandry of aquatic animals has been given much attention. The development of prawn farms where the environment and feeding are under strict control is now beginning.

The Japanese have been developing farming systems for decades and have produced much useful information. The application of some of these findings is now taking place to develop food and food systems for the developing aquaculture industries.

\section{Culture of larvae to metamorphosis}

All aquaculture systems depend upon an adequate supply of juvenile animals. In the Far East, prawn juveniles may be obtained directly from the oceans, whilst in the USA it is more usual to collect gravid females and allow them to spawn. This situation has arisen since it is not yet feasible to breed Penaeid prawns in captivity with any degree of reliability. The giant freshwater prawn Macrobrachium rosenbergii breeds well in captivity and has been used as the basis of a commercial enterprise in Hawaii. The production of seed is of major importance and requires a high degree of expertise. Fig. $I$ indicates the operations required to produce seed from Penaeid prawns and Macrobrachium.

The nutrition of larvae is not well understood and it appears that the most important consideration may be that a live food of the correct size is required; this 34 (I) 5 
Penaeids

Collect gravid females

from the sea (March-August)

Transport to spawning tanks:

three females $/ \mathrm{m}^{3}$ (USA);

one-two females $/ \mathrm{m}^{3}$ (Japan)

Remove females after deposition of eggs (300 000)

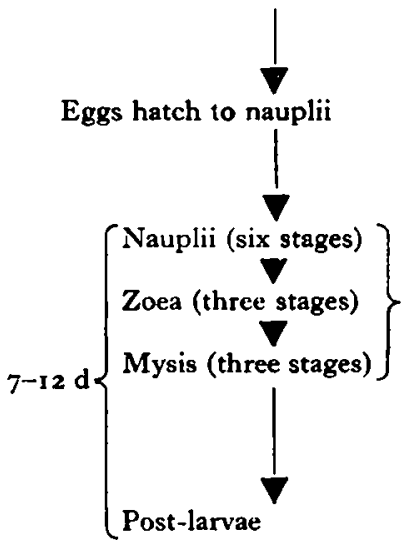

FOOD

Diatoms,

Artemia,
oyster eggs

Minced

fish, clams etc.
Macrobrachium

Mate ovigerous female with suitable male

Berried female: one animal/6o 1 tank. Eggs (30000-50 000) attached to female

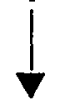

Zoea larvae hatch directly from the female egg mass carried at the base of the swimmerets

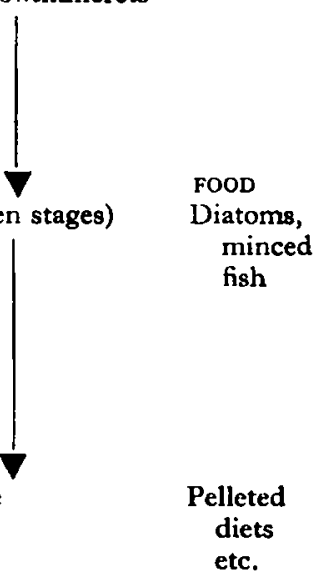

etc.

Fig. 1. The production of seed from Penaeid prawns and Macrobrachium rosenbergii.

may be a variety of diatoms or Artemia nauplii. The type of feed is important in that Artemia nauplii raised from cysts from the Utah region of the USA are nutritionally inferior to those of San Francisco Bay.

Analysis of the two forms of Artemia reveals little, if any, difference and as yet it is not known why one should prove superior to the other.

Prawn larvae have been reared on synthetic diets, especially micro-encapsulated preparations, but with low survival rates.

Minced fish food is required for the later larval stages and this indicates the change from a vegetarian to an omnivorous or carnivorous state. Once fully metamorphosed, the post-larvae graze upon algae and decaying organic matter from the substratum. Post-larvae are fed on a finely ground, pelleted diet which possesses a moderate degrec of buoyancy.

\section{Culture methods for juvenile to adult prawns}

There are several basic methods of crustacean aquaculture, which are as follows.

I. Extensive culture. In this system crustaceans are introduced into large outdoor ponds or enclosures. 'The density of animals per $\mathrm{m}^{2}$ floor area is low. The animals rely on natural production of food by the pond, but in order to increase pond productivity, fertilizers are sometimes added. 
2. Intensive culture. This system consists of smaller outdoor ponds or tanks in which prawns are stocked at high density. Usually the ponds are well-constructed and possess facilities for increasing aeration and water exchange. The animals rely on pond productivity for food, but often supplementary fish or pelleted diets are necessary for optimum grow-out.

3. Indoor intensive. This system necessitates a high degree of control of the environment. Tanks are stocked at high densities of animals and food is provided in the form of fish fragments or pelleted diets. In order to prevent fouling of the system, it is necessary to circulate water through the tank to maintain a high level of oxygenation. The polluted overflow water may be run to drain or recycled through a biological filter.

\section{Practical aquaculture systems}

The most widely used aquaculture system is the well-established extensive method of the south-east Asian countries. In its simplest form the grow-out ponds consist of earth banks arranged in a square or rectangle: water is supplied to the ponds by means of sluice gates which open into a river or estuary, and in order to create a water flow, the pond floors are lower than the minimum water level of the river.

In Japan the sluice gates, which possess a screen, are permanently open so that tidal action causes inflow of fresh water and food. Due to the muddy nature of the pond bottom, decomposition of organic matter frequently causes reduced oxygen tensions in the lower regions of the pond. The water is usually aerated by paddle wheels to raise dissolved oxygen levels.

In south-east Asia about twenty-five species of crustaceans are cultivated, about one-third extensively in ponds, and the remainder on small establishments or experimental units. In Japan, the Kuruma prawn (Penaeus japonicus) is the most important species and is cultured by the extensive method. The present output is about 200 tons per annum. The main areas of aquaculture are the Philippines and Indonesia, where $\mathrm{I} 70000 \mathrm{ha}$ are in use at present. The estimated output of prawns from such systems is $2000 \mathrm{~kg} / \mathrm{ha}$, but it is hoped eventually to achieve $5000 \mathrm{~kg} / \mathrm{ha}$. At present, about 10000 ha are being developed for prawn production.

In order to increase the output of the ponds, prawns are frequently reared along with milkfish, a method known as polyculture. This method is used in China, Philippines and Indonesia for Penaeus monodon and Metapenaeus monoceros.

Lobsters and crabs are also being cultured, but only experimentally at present.

\section{Culture systems for nutritional trials}

Pond and lagoon culture has produced crops of prawns, but the output has been low and variable. Animals have also been successfully reared in controlled systems in the laboratory where artificial foods were given.

The route to the economic farming of prawns lies in determining the precise nutritional requirements at all stages of development of the animal and the development of an inexpensive artificial diet from readily available foodstuffs. Pelleted diets, consisting of various fish meals, soya bean and starch, have been designed for 
various species but with results which are inferior to those obtained for animals fed on 'natural' foods such as clams etc. It has proved difficult to maintain a $70 \%$ efficiency as compared to a natural diet, with an inexpensive pelleted ration.

The study of the nutrition of aquatic animals is difficult on account of the environment. It is therefore essential that a suitable experimental culture system is devised which will permit acceptable growth and survival of the animal under investigation. A system which imposes a restraint on the growth of the animal will not reveal nutritional differences in experimental diets. Systems are frequently designed for the benefit of the user and not the animal. 'The following factors are of key importance in the design of an experimental unit for the study of crustacean nutrition.

r. The water temperature must be maintained accurately at the desired level $\pm 0.5^{\circ}$ by means of a thermostated heater.

2. The water must be circulated to maintain a high level of oxygenation. A value of $80 \%$ saturation or more is required for crustaceans. The circulated water may be run to waste or re-cycled through a gravel filter to remove toxic metabolites such as ammonia. In systems where tropical animals are being reared, recycling of water is vital to the economics of the process.

3. The tank size, shape, colour, texture and material must not influence animal behaviour patterns.

4. The correct stocking density must be used; in the instance of crustaceans this is usually a single animal per tank.

5. The diet must be of the correct size range, texture and buoyancy, and presented at the correct time of day. Excess diet must be removed, dried and weighed, otherwise the animal returns to fecd on the nutritionally inferior diet. Normally a crustacean will feed within $\mathrm{I} h$ if diet is presented at the correct time. The soluble components of the diet begin to leach out immediately the diet becomes saturated with water; it is therefore vital to ensure that only diet in prime condition is eaten by the experimental animals. An experiment set up to determine the leaching rate of vitamins from a pelleted diet revealed that over $90 \%$ of the thiamin had leached from the diet within $\mathrm{I} 8 \mathrm{~h}$ of submergence.

6. The experimental results must be acquired by careful handling of the animals. Weight gain must be assessed at intervals which do not interfere with the growth of the animal. For prawns, an interval of $4^{-6}$ weeks per weighing is possible. An indirect assessment of growth rate may be made from the length of the shed exoskeleton at the time of moulting. The distance from the posterior margin of the orbit of the eye to the posterior margin of the carapace or telson is proportional to the weight of the animal. The weight of an animal may be estimated graphically in this manner (K. J. Wildish, unpublished results).

7. It is important to compare different diets on juvenile animals of the same brood. There are noticeable differences in performance between the offspring of different adults. In order to select an animal which is suitable for a nutritional trial, a group of about ten animals is reared. After a period of 6 weeks, the dominant animal of the group is selected for further trials. In this way, the animal most likely to perform well in the trial is selected. 
8. The method of testing diets which has been described will compare diets of differing constituents but will not in any way represent a diet which may be successfully used for grow-out in an aquaculture system. It may be necessary to increase the energy content of a diet which performs well with individual animals kept in a small tank, since in larger tanks the animals are far more mobile.

9. The preparation of the diet is important since it is necessary to bind the food ingredients to prevent disintegration of the pelleted diet in water. A restriction on the use of binders is the cost and availability. An alternative approach is to incorporate foodstuffs with inherent binding properties into the diet. This technique has been used by the Lord Rank Research Centre, Balazs, Ross \& Brooks (1973) of the Hawaii Institute of Marine Biology, and by Hastings (I969).

\section{Crustacean nutrition}

Most modern crustacean diets are based on the work of the Japanese and have not been changed other than to replace unavailable Japanese products by similar foodstuffs, available in the locality. A further restriction is brought about by the fact that the Japanese incorporate 'fresh' ingredients such as squid and clams into diets; these would prove to be too expensive elsewhere. A typical modern diet (Deshimaru \& Shigeno, 1972) contains the following ingredients: squid meal, fish meal, whale meal, Mysid shrimp meal, yeasts, soya-bean protein, active sludge, casein, gluten, starch, vitamin mixture, mineral salt mixture.

The vitamin mixture contains the following vitamins: thiamin hydrochloride, riboflavin, pyridoxine hydrochloride, cyanocobalamin, nicotinic acid, calcium pantothenate, biotin, myo-inositol, pteroylmonoglutamic acid, choline chloride, $p$-aminobenzoic acid, menadione, $\alpha$-tocopherol, ascorbic acid ( $\mathrm{Ca}$ salt), retinol, cholecalciferol, cholesterol.

The salt mixture (mineral) is as follows: $\mathrm{K}_{2} \mathrm{HPO}_{4}, \mathrm{Ca}_{3}\left(\mathrm{PO}_{4}\right)_{2}$, calcium lactate.

Balazs et al. (1973) used the following ingredients in their trials: soya-bean meal, Hawaiian fish meal, shrimp meal, brewers' yeast, ground maize, high-gluten wheat flour, $\mathrm{Ca}_{3}\left(\mathrm{PO}_{4}\right)_{2}, \mathrm{NaCl}$ (iodized), traces of manganese, iron, copper, cobalt and zinc, micro-ingredient mixture.

The micro-ingredient mixture was similar in composition to that of Deshimaru \& Shigeno (1972) with the inclusion of an antioxidant, butylated hydroxytoluene.

A recent formula employed by the Lord Rank Research Centre (Walker, unpublished results) incorporated the following: wheat flour, cod-liver oil, prawn meal, soya-bean meal, microbial protein, casein, herring meal, white fish meal, vitamin mixture (based on Japanese formula).

The protein content of most modern diets is between 300 and $600 \mathrm{~g} / \mathrm{kg}$. It has been the practice to formulate a diet having a similar amino acid distribution to that of the test animal. Table I gives the amino acid composition of the tail flesh of the Penaeid sea-water prawn Penaeus japonicus and freshwater Malaysian prawn Macrobrachium rosenbergii. 
Table I. Amino acid composition ( $\mathrm{g} / \mathrm{kg}$ dry weight) of the tail flesh of the Penaeid sea-water prawn Penaeus japonicus and the fresh-water Malaysian prawn Macrobrachium rosenbergii

Aspartic acid
Threonine
Serine
Glutamic acid
Proline
Glycine
Alanine
Cystine
Valine
Methionine
Isoleucine
Leucine
Tyrosine
Phenylalanine
Lysine
Histidine
Arginine

\begin{tabular}{|c|c|}
\hline P. japonicus & $M$. rosenbergii \\
\hline $\begin{array}{l}79 \cdot 7 \\
29 \cdot 8\end{array}$ & $\begin{array}{l}79 \cdot 9 \\
25 \cdot 7\end{array}$ \\
\hline $\begin{array}{r}30.4 \\
116.6\end{array}$ & $\begin{array}{l}24.9 \\
86.7\end{array}$ \\
\hline $25 \cdot 7$ & $16 \cdot 8$ \\
\hline $34^{\circ} 5$ & $4 I \cdot 3$ \\
\hline 40.7 & $32 \cdot 1$ \\
\hline $7 \cdot 7$ & 9.5 \\
\hline $\begin{array}{l}30.3 \\
19.8\end{array}$ & $\begin{array}{l}31 \cdot 3 \\
28 \cdot 6\end{array}$ \\
\hline $3 I \cdot 3$ & $27 \cdot 3$ \\
\hline 54.9 & $46 \cdot 9$ \\
\hline $28 \cdot 7$ & $27 \cdot 3$ \\
\hline $33 \cdot 0$ & $30 \cdot 1$ \\
\hline $\begin{array}{l}57 \cdot 8 \\
16 \cdot 4\end{array}$ & $\begin{array}{l}74 \cdot 2 \\
38.9\end{array}$ \\
\hline $55 \cdot 7$ & $57 \cdot 8$ \\
\hline
\end{tabular}

\section{Protein metabolism}

Many workers have found that in a balanced diet, the growth rate of the crustacean may be correlated with the level of dietary protein. At protein levels of $600 \mathrm{~g} / \mathrm{kg}$ and more, a high food conversion efficiency is demonstrable (Deshimaru \& Shigeno, 1972). Nose (1964) observed that the digestive efficiency of both the crayfish (Procambarus clarkii) and the prawn (Penaeus japonicus) increased with increasing level of crude dietary protein.

Nose (1964) obtained values of $9 \mathrm{I}-99 \%$ absorption for albumin and casein by crayfish. The digestive absorption efficiency of prawns for compounded diets was $85-88 \%$. Forster \& Gabbott (197I) also found high values of assimilation efficiency in Palaemon serratus and Pandalus platyceros. Values ranged from $79.6 \%$ for whale meat to $97.7 \%$ for casein in Palaemon serratus; Pandalus platyceros assimilated white fish meal at $75.4 \%$ efficiency.

The essential amino acids of prawn species have been determined for Palaemon serratus by Cowey \& Forster (1971) and Macrobrachium rosenbergii by Walker (unpublished results). In both instances the isotopic tracer method developed by Zandee (1966) was used. The method involves the injection of $\left[\mathrm{U}-{ }^{14} \mathrm{C}\right]$ acetate into the prawn haemocoel. After a few days, the prawns are killed and fractionated. The protein fraction is hydrolysed and separated into the constituent amino acids on a chromatography column. The concentration of amino acid and extent of labelling is estimated. Weakly labelled amino acids are considered to be essential to the prawn since they are not readily synthesized.

Cowey \& Forster (197I) attempted to supplement, with amino acids, diets known to be low in essential amino acids. However, supplementation of gelatin and zein diets with tryptophan, and lysine plus tryptophan, did not improve the nutritional value. 
Kitabayashi, Schudo, Nakamura \& Ishikawa (1971) studied the effect of supplementing the diet of Penaeus japonicus with methionine and arginine. Methionine improved growth rate when given at a level of $5.2 \mathrm{~g} / \mathrm{kg}$, but inhibited growth rate at higher levels. Arginine which was given in place of dietary squid meat also improved the growth rate of prawns at a dietary level of up to $8.3 \mathrm{~g} / \mathrm{kg}$; at levels above this, the growth rate fell to that of controls. Kitabayashi et al. (197I) concluded that the growth-promotion effects of dietary squid meat extract were dependant upon its high arginine content.

It is apparent that the quality of dietary protein is important for high growth rate. However, it has been demonstrated that the food texture or gross structure is also of importance (Forster \& Beard, 1969). Mussel mantle which has been freeze-dried, ground and re-constituted with a guar gum binder is only $48 \cdot \mathrm{r} \%$ efficient in growth promotion compared with untreated mussel mantle.

\section{Carbohydrate metabolism}

The carbohydrate metabolism of prawns is closely involved with chitin synthesis, since a high percentage of injected $\left[\mathrm{U}-{ }^{14} \mathrm{C}\right.$ ] glucose is incorporated into the chitinous exoskeleton of the prawn. The significance of carbohydrate metabolism in crustaceans is not fully understood. It has been observed that in starved Hemigrapsus the tissue glycogen remains constant, whilst in $U c a$ and barnacles a decrease is observed. The glycogen level of the crustacean fluctuates markedly according to the stage of the moult cycle. Maximum glycogen levels occur at the late pre-moult stage and fall to a minimum at the post-moult stages.

A starved animal may exhibit a fall in respiratory quotient (RQ). Mieenakshi \& Scheer (196I) observed that the RQ of Hemigrapsus fell from $1 \cdot 0$ to 0.76 during fasting. It is therefore essential to ensure that the carbohydrate fraction of the diet is sufficient to avoid protein catabolism.

\section{Fatty acid and sterol metabolism}

The synthesis of fatty acids from acetate and the interconversion of dietary sterols has been studied in a number of crustaceans. Teshima \& Kanazawa (1971) examined the sterols of Penaeus japonicus by gas-liquid chromatography and revealed that the main sterol was cholesterol. Injected radioactive acetate failed to produce labelled sterols in all crustaceans investigated by these workers, who suggested a lack of synthetic ability.

The dietary cholesterol requirement of Penaeus japonicus was determined by Kanazawa, Tanaka, Teshima \& Kashiwada (1971) who considered a level of $5 \mathrm{~g} / \mathrm{kg}$ diet produced optimal growth rate.

The proportions of the various fatty acids of Artemia are similar to those of the diet, with the exception of oleic, linolenic, stearic and a $\mathrm{C}_{20}$ pentaenoic acid, which occur at higher concentration. Hinchcliffe \& Riley (1972) considered that these were synthesized by Artemia from the $\mathrm{C}_{\mathbf{1 6}}$ acids of the planktonic diet. 


\section{Vitamin requirements}

The knowledge of vitamin requirements in crustaceans is scant. Most information has been obtained from a limited number of species, chiefly Artemia, Daphnia and Oniscus (Hartenstein, 1970).

Vitamin A has been identified in Penaeid prawns by Fisher, Kon \& Thompson (1957), otherwise there is no detailed information of the vitamin requirements of prawns.

\section{The growth of prawns fed on artificial diets}

The growth rate of the prawn Macrobrachium rosenbergii depends upon: age and sex of animal, genetic influences of parents, type, rate and frequency of feeding, disease, and environmental factors, such as stocking density, temperature, oxygen tension, tank design and water quality in terms of waste products.

Table 2 shows the growth performance of male and female Macrobrachium rosenbergii fed on a compounded diet $(400 \mathrm{~g}$ protein $/ \mathrm{kg})$.

Table 2. Growth performance of two typical Macrobrachium rosenbergii adults

\begin{tabular}{|c|c|c|c|c|c|c|}
\hline $\begin{array}{l}\text { Age } \\
\text { (d) }\end{array}$ & \multicolumn{2}{|c|}{$\begin{array}{l}\text { Body-weight } \\
\text { (g) }\end{array}$} & \multicolumn{2}{|c|}{$\begin{array}{c}\text { Rate of } \\
\text { body-weight gain } \\
\text { (mg/g per } \mathrm{d})\end{array}$} & \multicolumn{2}{|c|}{$\begin{array}{c}\text { Food conversion } \\
\text { ratio }\end{array}$} \\
\hline $\begin{array}{l}162 \\
204\end{array}$ & $\begin{array}{c}\delta \\
8 \cdot 45 \\
26 \cdot 84\end{array}$ & $\begin{array}{c}\stackrel{9}{7} \\
5 \cdot 45 \\
14.68\end{array}$ & $\begin{array}{c}\delta \\
19.5 \\
27.8\end{array}$ & $\begin{array}{c}+9 \\
17 \cdot 1 \\
23 \cdot 8\end{array}$ & $\begin{array}{c}\delta \\
2 \cdot 71 \\
1 \cdot 20\end{array}$ & $\begin{array}{c}q \\
5 \cdot 52 \\
1 \cdot 62\end{array}$ \\
\hline $\begin{array}{l}240 \\
300\end{array}$ & $\begin{array}{l}35 \cdot 20 \\
76 \cdot 62\end{array}$ & $\begin{array}{l}19 \cdot 10 \\
27 \cdot 19\end{array}$ & $\begin{array}{r}7.4 \\
13.2\end{array}$ & $\begin{array}{l}7 \cdot 1 \\
5 \cdot 8\end{array}$ & $\begin{array}{l}3.50 \\
1.90\end{array}$ & $\begin{array}{l}3.75 \\
3.63\end{array}$ \\
\hline
\end{tabular}

The values in Table 2 represent the growth rates of two experimental animals reared individually in 601 polythene tanks. It is apparent that the growth rate of the female is considerably less than that of the male. The difference of growth rate is not apparent before the animals become sexually differentiated; this usually occurs at a body-weight of $\mathrm{I}-3 \mathrm{~g}$.

As a comparison with the idealized growth rates presented in Table 2, Table 3 indicates the growth rates of various species capable of being cultured. The values refer to growth during a certain time period in an extensive pond system.

Table 3. Growth performance of crustacean species during aquaculture

\begin{tabular}{lcc}
\multicolumn{1}{c}{$\begin{array}{c}\text { Weight gain } \\
\text { Species }\end{array}$} & $\begin{array}{c}\text { (post metamorphosis) } \\
\text { (g) }\end{array}$ & $\begin{array}{c}\text { Time taken to } \\
\text { achieve this weight }\end{array}$ \\
Penaeus japonicus & 15 & 5 months \\
Penaeus monodon & 22 & 6 months \\
Penaeus orientalis & 30 & 4 months \\
Penaeus setiferus & 30 & 12 months \\
Macrobrachium rosenbergii & 60 & 6 months \\
Homarus americanum & 1000 & 3 years
\end{tabular}


The average edible crustacean possesses a great potential for rapid growth rate whilst maintaining a high efficiency of food conversion. It is possible to maintain a growth rate of $20-50 \mathrm{~g} / \mathrm{kg}$ body-weight per $\mathrm{d}$ at a food conversion ratio ( $\mathrm{g}$ dry food consumed/g increase in wet weight) of less than 1.5 , when a high-protein (400 $\mathrm{g}$ protein $/ \mathrm{kg}$ or more) diet is given.

The major problem is to reduce dietary cost while maintaining high efficiency. The incorporation of new low-cost foodstuffs into prawn rations will eventually permit the development of high-performance diets in the near future. Providing the problems of husbandry associated with increased intensification of the process are not insuperable, it may soon be possible to supplement the rapidly increasing shellfish market with artificially reared animals.

\section{REFERENCES}

Balazs, G. H., Ross, E. \& Brooks, C. C. (1973). Aquaculture 2, 369.

Cowey, C. B. \& Forster, J. R. M. (1971). Mar. Biol., Berlin ro, 77.

Deshimaru, O. \& Shigeno, K. (1972). Aquaculture I, II5.

Fisher, L. R., Kon, S. K. \& Thompson, S. Y. (1957). Y. mar. Biol. Ass. U.K. 36, 501.

Forster, J. R. M. \& Beard, T. E. (I969). Cons. perm. int. Explor. Mer CM 1969/E no. 6.

Forster, J. R. M. \& Gabbott, P. A. (197I). F. mar. Biol. Ass. U.K. 5I, 943.

Hartenstein, R. (1970). In Comparative Biochemistry of Nitrogen Metabolism [J. W. Campbell, editor]. New York: Academic Press.

Hastings, W. H. (1969). EIFAC tech. Pap. no. 9, p. 23.

Hinchcliffe, P. R. \& Riley, J. P. (1972). F. mar. Biol. Ass. U.K. 52, 203.

Kanazawa, A., Tanaka, N., Teshima, S. \& Kashiwada, K. (1971). Bull. Fap. Soc. scient. Fish. 37, 211.

Kitabayashi, K., Schudo, K., Nakamura, K. \& Ishikawa, S. (1971). Bull. Tokai reg. Fish. Res. Lab. 65, 119.

Meenakshi, B. R. \& Scheer, B. T. (1961). Comp. Biochem. Physiol. 3, 30.

Nose, T. (1964). Bull. freshwat. Fish. Res. Lab., Tokyo 14, 24.

Teshima, S. \& Kanazawa, A. (1971). Bull. Jap. Soc. scient. Fish. 37, 63.

Zandee, D. I. (1966). Archs int. Physiol. Biochim. 74, 6r 4. 